\title{
Control de la contaminación biológica en los laboratorios de docencia de la Universidad Colegio Mayor de Cundinamarca en Bogotá, Colombia
}

\author{
Alicia Álvarez de Weldefort ${ }^{1}$ y Silvia E. Campuzano F. $\quad{ }^{1 *}$ \\ ${ }^{1}$ Programa de Bacteriología, Facultad de Ciencias de la Salud, Universidad Colegio Mayor de Cundinamarca, Bogotá, Colombia. \\ Recibido: 23-07-03; Aceptado: 28-09-03
}

\begin{abstract}
RESUMEN
Se diagnosticó en el programa de Bacteriología y Laboratorio Clínico al riesgo biológico como el de mayor incidencia en las prácticas académicas. Este diagnóstico fue sustentado por los análisis microbiológicos. Se procedió a aplicar la medida correctiva por acciones de prevención, conducentes al mejoramiento de la calidad de vida y desarrollo de la responsabilidad frente al cuidado del medio ambiente. El programa educativo que se aplicó se denominó Estrategias para una Nueva Cultura en Bioseguridad . Luego de ser aplicado a los diferentes estamentos universitarios se procedió a monitorear nuevamente la contaminación de los laboratorios, controlando la experiencia mediante la evaluación de las mediciones propuestas de eficacia, cobertura, eficiencia y efectividad. Se concluyó que la educación continuada y permanente desarrollada mediante un programa flexible, disminuyó significativamente la presencia de patógenos en los laboratorios.

Palabras claves: Contaminación biológica, prevención, control microbiológico, cultura de bioseguridad, educación.
\end{abstract}

\section{ABSTRACT}

Biological contamination's control in the teaching laboratories at the Colegio Mayor de Cundinamarca University in Bogotá , Colombia.

Once it was known the assessment about the problems related to the biological contamination that in the panorama of risks at the Health Sciences School highest incidence was found, the biological risk directly involving the performance of daily laboratory tasks. This finding was supported by the microbiological analysis and the prevention measures were implemented through an educational program, in order to reach a change towards a new culture of risks prevention, and to take care of oneself, to find a better quality of and to be able to develop the responsibility to take care of the environment. The educational program used was named Strategies for a New Biosecurity Culture and it was developed since the knowledge about the environment, the community and the agent. This educational program was implemented to teachers, to managing and to people who work in general services, then the evaluation was followed by an assessment of contamination

\footnotetext{
* Correspondencia: scampuzano@hotmail.com/scampuzano@unicolmayor.edu.co
} 
levels in the laboratories, and this experience was evaluated by the indicator proposed, related to efficiency, efficacy and effectively.

The results of the study was to know that a continuous and permanent educational program teaching since a flexible program development with special strategies that integrate about to be able to form an opinion, to be in the own context and to be innovating, and that if this knowledge is developed since the inducement, the present time, the new training and the evaluation so it was possible to obtain a significance decrease in the appearance of pathological microorganisms in labs.

Key words: Biological contamination, prevention, microbiological control, biosecurity culture, teaching.

\section{Introducción}

El control de riesgo biológico se fundamenta en el manejo de la prevención, entendida como la aplicación de políticas claras que se relacionen con la educación, la investigación y la vigilancia.

En el presente estudio se unen la investigación y la educación para validar la efectividad de esta última en el proceso de cambio de actitudes frente a las diferentes problemáticas. En el caso actual, frente al control de la diseminación de la contaminación, generada por la manipulación del material biológico, situación intrínseca en el desarrollo de las actividades del estudiante y del profesional de bacteriología.

Luego de realizado el diagnóstico de la contaminación ambiental microbiológica del medio ambiente y de los individuos analizados en su microbiota y flora patógena presente, se diseñó, implementó y desarrolló un programa educativo tendiente a conseguir mejorar la calidad de vida y las condiciones de trabajo con el objetivo de lograr mayor productividad y menor ausentismo laboral.

La medida del impacto del proceso educativo se validó con los indicadores de asistencia al curso, el número de actividades implementadas y el uso de los elementos de protección personal.

El éxito de las acciones educativas desarrolladas se valoró mediante la evaluación de patógenos en ambiente, equipos e individuos, por medio de estudios microbiológicos validados por los indicadores relacio- nados con: presencia de patógenos y presencia de flora normal, tanto de hongos como de bacterias.

Los análisis microbiológicos se realizaron de acuerdo a los estándares y protocolos pertinentes para cada caso.

\section{Materiales y métodos}

La muestra investigada correspondió a los once laboratorios de práctica y al laboratorio central; donde se realizaron cultivos de medio ambiente para hongos y bacterias.

Se practicaron 120 cultivos para hongos y 120 para bacterias, analizando mesones, paredes, vertederos y equipos, en cada uno de los laboratorios.

El estudio se desarrolló entre febrero del año 2000 y junio del 2001, llevándose a cabo en tres etapas: en la primera se evaluó la contaminación ambiental presente en los laboratorios; en la segunda se aplicó el programa educativo y, en la tercera, se midió el impacto del programa educativo mediante la evaluación comparativa de la contaminación ambiental en los laboratorios y los equipos.

El programa educativo se abordó a partir de tres elementos directamente relacionados con la problemática:

Ambiente: Considerado como la necesidad de un ambiente seguro, libre de patógenos.

www.unicolmayor.edu.co 
Individuos:Considerado como la opción de contagio del personal que labora con material biológico y la posibilidad de contaminación microbiana.

Agente: Considerado como la población de hongos, bacterias, virus y parásitos patógenos capaces de infectar al individuo.

Se evaluó de acuerdo a los indicadores de asistencia al curso, actividades implementadas y uso de elementos de protección personal.

\section{Valoración de la contaminación}

En los once laboratorios de práctica se realizaron cultivos de bacterias y hongos a paredes, mesones, equipos, vertederos y ambiente. En el laboratorio central se estudiaron las áreas del cuarto frío, zona de esterilización y de materiales.

Los análisis se realizaron de acuerdo a la norma microbiológica estándar para estos casos. Los resultados de los cultivos se expresaron en frecuencias de porcentajes, se graficaron en histogramas y tortas con relación a los indicadores propuestos de: presencia de patógenos y no patógenos para ambiente, equipos y superficies; además se evaluó la presencia de flora normal y de patógenos en grupos de control.

\section{Resultados}

El programa educativo enfatizó temáticas de actualidad y de importancia para cada uno de los elementos propuestos así:

- Ambiente:Se refirió a la aplicación de las normas de asepsia, antisepsia, esterilización y desgerminación con el fin de evitar la diseminación de cualquier agente infeccioso. Se incluyó manejo y limpieza de paredes, mesones, vertederos y equipos.

- Individuos:Se refirió a los cuidados que debe tener el profesional que manipula el agente biológico, se enfatizó en normas universales de bioseguridad, lavado de manos, uso de cabinas de seguridad, duchas, medidas para evitar accidentes y plan de contingencia.
- Agente: Se caracterizaron los microorganismos más comúnmente involucrados en la contaminación a partir del manejo de fluidos biológicos y se estudiaron sus principales vías de transmisión. Estos agentes tienen como fuente principal las muestras biológicas que deben manipularse constantemente durante el desarrollo de las prácticas; por consiguiente esta temática se abordó desde el transporte, tipos, manipulación, condiciones y remisión de muestras, manejo de sangre y de desechos.

\section{Indicadores de proceso}

$$
\begin{aligned}
& \frac{\text { No. de usuarios del programa }}{\text { Total de individuos }}=\frac{900 \text { est. }}{1.000}=0.9 \\
& \frac{\text { No. de asistentes a actividades educativas }}{\text { No. de individuos objetos del programa }}=\frac{800}{1000}=0.8 \\
& \frac{\text { No. uso de elementos de protección personal }}{\text { No. individuos objeto del programa }}=\frac{900}{10}=\frac{90.9}{100}
\end{aligned}
$$

\section{Contaminación ambiental}

Se encontraron hongos en un $36 \%$ de los cultivos realizados, bacterias en un $40 \%$ de las muestras analizadas (Figura 1).

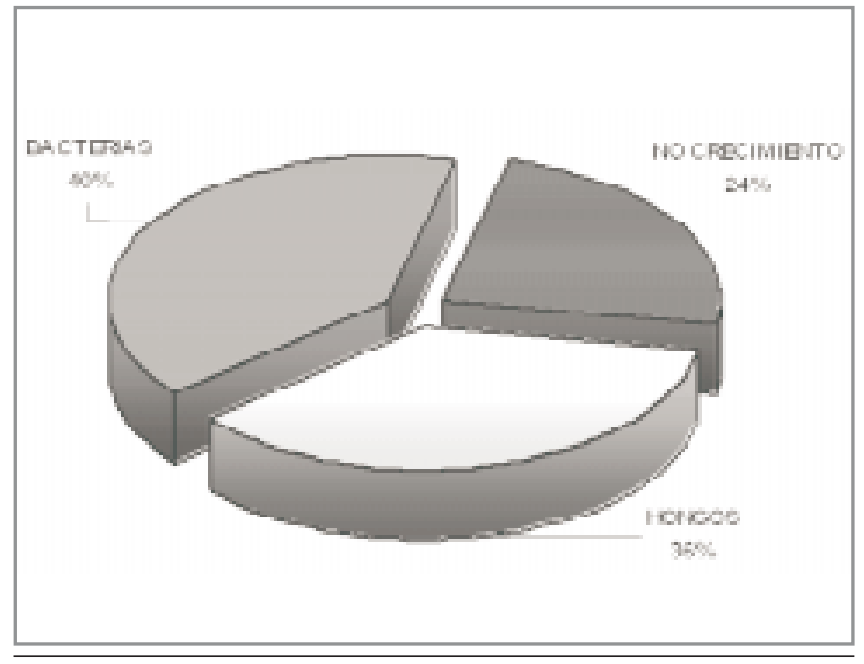

Figura 1. Flora Bacteriana y Micótica en los laboratorios. 
La mayoría de bacterias que componían el 40\% de positividad en los cultivos del ambiente, de equipos y de superficies, correspondían a bacterias no patógenas. Como patógenas sólo se detectaron 3\% de bacterias gram negativas entéricas caracterizadas comoEnterobacter sp y E-coli.

\section{Discusión}

Dentro de las actuales políticas de gestión en salud surge una prioridad y es precisamente la prevención, entendida como la generación de una cultura orientada hacia el autocuidado que proteja al equipo de salud, al paciente, a su familia y a la comunidad en general del riesgo de contraer enfermedades.

Desde el punto de vista de normatización de la Secretaría de Salud, el trabajo diario en los laboratorios de diagnóstico, como consecuencia del material biológico que debe ser manipulado como esencia de su quehacer cotidiano, los convierte en áreas críticas de alto riesgo.

La universidad es el sitio ideal para lograr la capacitación y formación adecuada de los profesionales de la salud, en este caso, de las bacteriólogas, en cuanto al manejo de material biomédico que genera riesgo biológico; así mismo, se debe inculcar la cultura de prevención, que debe guiarles en el desempeño de su vida profesional y personal; y prepararlos para que se comprometan en el autocuidado y puedan liderar campañas de prevención de la enfermedad con la comunidad en general, según su desempeño profesional.

La mejor herramienta con que cuenta la prevención es la educación, como medio de generar cambios de actitud y formación de nuevos hábitos; por esta razón se determinó probar en esta investigación la eficiencia en la aplicación de un programa educativo como elemento correctivo que generara el control de la contaminación biológica presente en los laboratorios

www.unicolmayor.edu.co de diagnóstico, como parte de la docencia en nuestra universidad.

En consecuencia, se aplicó un esquema educativo de reforzamiento en el tema de bioseguridad, con el propósito de lograr un ambiente de trabajo ordenado y seguro que condujera simultáneamente a mejorar la calidad, reducir los costos de operación y alcanzar óptimos niveles de funcionalidad. Para este logro se necesita establecer responsabilidades y dirección con la participación consciente de todos los estamentos humanos involucrados en el proceso y se requiere producir la confianza y la estimulación para alcanzar su fin como lo plantea Nelly Betances de Holguín (4).

En el desarrollo profesional como lo indica el doctor Malagón (5), el costo de la infección es muy alto en todo sentido y, por consiguiente, se debe determinar la actitud permanente de prevención y control si no queremos que esta debilidad cobre vidas humanas; la situación se pone más crítica si la atención es de baja calidad, de hecho, estas circunstancias colocan al profesional de salud frente a una responsabilidad muy grande, lo cual le obliga a desarrollar actitudes precisas, ágiles y oportunas.

Es así como, para responder a este gran reto, el modelo educativo que se empleó para sensibilizar a la comunidad universitaria, se diseñó de acuerdo con las estrategias educativas planteadas en una didáctica que unía el método de la concientización o de pedagogía liberadora y el método participativo, centrado en el desarrollo humano según los planteamientos de María Teresa Cerquera (1).

Es muy satisfactorio poder presentar los resultados de los indicadores propuestos para la evaluación del proceso educativo, cuyas cifras de 0.9 de asistencia a las actividades propuestas indican buena acogida por parte del estudiantado; de igual manera, 0.9 para el uso de elementos de barrera es un indicativo de la toma de conciencia de la importancia de prevenir el riesgo. 
El éxito del programa se pudo corroborar con la evaluación de la contaminación del ambiente que disminuyó significativamente la presencia de patógenos presentes en ambientes, equipos y paredes en los 120 cultivos practicados para diagnóstico de bacterias, 120 cultivos para diagnóstico de hongos. Solamente se encontraron tanto bacterias como hongos comúnmente presentes en ambientes de laboratorio considerados como flora normal; además que se hallaron en cantidades menores que las encontradas en la evaluación diagnóstica practicada antes del proceso educativo.

En consecuencia, se concluye que definitivamente una educación significativa, motivadora, flexible, que comprometa la responsabilidad individual con proyección hacia sus semejantes, es el mejor control en el caso de enfrentar el riesgo biológico.

La transformación que actualmente se vive en el ámbito universitario y, por lo tanto, en nuestra universidad, constituye una gran fortaleza, ya que tanto el sector educativo como el sector de la salud están emprendiendo adecuaciones y nuevas políticas conceptuales y operativas que conllevan a romper barreras y a proyectar trabajos aunados, coordinando acciones mediante proyectos conjuntos en este sentido. Esta investigación se enmarcó dentro de la concepción del trabajo con la comunidad universitaria detectando necesidades específicas y lograr así identificar las prácticas con sus riesgos y las estrategias propias que conlleven a una motivación y formación que facilite los resultados deseados.

\section{REFERENCIAS}

1. Cerquera MI. Proponer la salud. Asesoría de la educación para la salud y participación social en la OPS - OMS. Washington D.C.; 1992.

2. Secretaría de Salud de Bogotá. División de Apoyo Laboratorio Central. Normas en el laboratorio clínico. Bogotá; 1993.

3. Álvarez A, Campuzano. Identificación de riesgos ocupacionales en los laboratorios de docencia. Bogotá; 1999.

4. Betances N. Elementos del programa de bioseguridad. Clínica Lab 1995; 7:12-18.

5. Malagón G. Infecciones hospitalarias. 2da. ed. Bogotá: Ed. Panamericana; 1999.

6. Novack LD. Constructivismo humano. Consenso Emergente. Ponencia Seminario Internacional Estrategias Educativas en la Enseñanza de las Ciencias; 1987.

7. Ministerio de Salud de Colombia. Decreto No. 1891. Fomento de la Salud y Prevención de la Enfermedad 1994, Ley 60 de 1993, Ley 1298 de 1994.

8. OPS. Las políticas de Promoción de la Salud. Conferencia Internacional. Bogotá; 1992.

9. Ministerio de Salud de Colombia. Ley 100. Sistema de Seguridad Social en Salud. Colombia; 1993.

10. Kerlinger F. Investigación del Comportamiento. México: Ed. Interamericana; 1975.

11. Fernández L, De la Cruz C. Riesgo Biológico Ocupacional y Medidas de Seguridad en los Laboratorios Médicos. Instituto de Medicina Tropical Kouri. CEPIS 1999. Disponible en: URL: http://www.cepis.ops-oms.org/eswww/fulltest/ repino61/rbomslm/rbooms.htm 